\title{
Design Recommendation Information Architecture of Hospital Website Using Bottom-Up Approach on Card Sorting Method
}

\author{
Risqi Puspa Dewi ${ }^{1}$, Mira Kania ${ }^{1}$, Veronikha Effendy ${ }^{1 *}$ \\ ${ }^{1}$ School of Informatics, Telkom University \\ Bandung, Indonesia \\ *veffendy@,telkomuniversity.ac.id
}

\begin{abstract}
One of the public facilities that use websites is the hospital. However, there are some shortcomings complained by users related to the hospital website, which is the lack of information, confusing view of the menu, etc. Therefore, we need the information architecture to manage related content and website structure. The build of information architecture is done by using a bottom-up approach in card sorting. There are five stages in the research, which the first stage is a strategy to equalize the goal in the development of the hospital website either from the point of view of the organization or company and the user's point of view of the hospital website. The second stage is a scope to find out what are the needs of the user in order to build the hospital website. The third stage is structure, which is the formation of the initial structure of information architecture by using a bottom-up approach to the card sorting method. The type of card sorting that is commonly used is the open card sorting. The fourth stage is the skeleton stage, which is used to make information architecture model design using wireframe and prototype. The fifth stage is the test using findability testing and usability testing. From the test, the design of information architecture is made to fulfill the desires and needs of users, as proven by the results of findability testing achieved 15.9 seconds, and the results of usability testing achieved 80.33 . Hence, by the results of these tests, it can be concluded that the design of information architecture at the hospital website has a good value from findability testing and usability testing.
\end{abstract}

Keywords: Information Architecture, Bottom-Up, Card Sorting, Usability Testing, Findability Testing

\section{INTRODUCTION}

W

EBSITES becomes one of the inseparable parts of our daily life. Sometimes, a website is a place to find any pieces of information and exchange them with each other [1]. One of the areas that use the website as a means of exchanging information is the hospital. With the website of the hospital, the user will be easy to find any information related to a hospital without visiting the hospital directly. However, a survey using questionnaires stated that information needed on the hospital website is still difficult.

The information architecture determines how to organize the content of a site, how to design the structure so that users can quickly find the required information [3]. Because information architecture deals with how 
people process information cognitively, information architecture considerations come in every product that requires users to reason from the information presented. Therefore, the information architecture is required for a hospital website to manage the organization, labeling, and navigating of a website [3] so that the information provided on the website is in accordance with the user's expectation. Thus, the information architecture of a hospital website must be built from the results of an individual assessment. A bottom-up approach and card sorting method are used to obtain such information architecture. The bottom-up approach is selected because the bottom-up approach is given a model of information structure that departed from user needs [4]. Whereas, the card sorting method itself is done because the technique of card sorting is useful in understanding the perceptions of users [5].

To see how far is the information architecture that has been created to meet the needs of users, findability testing, and usability testing are used [6]. Findability testing is a test conducted to determine how easy the user in finding information [7], whereas usability testing itself is one way to know the needs and desires of users [8]. By conducting analysis and implementation of information architecture for the hospital website, it is expected to assist the designing of hospital website applications in accordance with the desires and needs of users.

\section{LITERATURE REVIEW}

\section{A. Information Architecture (IA)}

Information architecture is commonly associated with websites and intranets, but can also be used in the context of any information structure or computer system. The effectiveness of information architecture is required for a company, or web-based system, which leads to users with high experience, and the goal of achievement is on findability and usability [6]. Information architecture determines how to organize the site content, how to design the structure so that users can quickly find the necessary information. The information architecture design should follow the principles that meet the needs and wants of users, not only to consider the relevance of the content but also to consider the user's convenience. In website design, information architecture design is essential. Information architecture within the site is to classify the contents of a website and create interactive navigation for content. With an unlimited amount of information and various backgrounds of users, it makes information architecture development should pay attention to the suitability to the user's habits and expectations. The website can facilitate users and attract users [3]. Information architecture can be in several meanings, which are [2]: structural designs designed for information dissemination; organizational combinations, labeling, searching, and navigation systems within websites and intranets; art and science of information and experience to support usability and findability; disciplines based on the principles of landscape design and architecture.

\section{B. Bottom-Up Approach}

The bottom-up approach for information architecture is derived from low-level categories and then groups into higher-level categories, where the user's needs look at existing products [4].

\section{Card Sorting}

Card sorting is the best method to create navigation and help in terms of understanding the needs of people as design materials [9]. Card sorting is a common usability technique, often used to find the user's mental model of information. Card sorting also has something to do with findability [10]. In this method, the user is asked to group the cards according to the category. Card sorting is also often used to assess the difference between a novice and an expert in understanding a system [11].

In this research, the type of card sorting used is open card sorting. Open card sorting is a method by which users will be given a card; then, the user can group the cards themselves according to the categories that are 
created by the user himself [9]. Open card sorting is for domain analysis, and to determine which structure will be the candidate. Open card sorting is used to understand the category of the user's mental model [12].

\section{Usability}

Usability is part of how the users are pleased when using the product. Usability testing is used to learn more about the characteristics of users, which are to determine how is the users thinking, how is the users' experience in using the website, how is the users' reactions to the website. By using that information, improvement to the website in terms of usability can be continued [8].

To perform usability testing will be used System Usability Scale (SUS). System usability scale is one of the surveys that can be used to assess the usability of various products or services [13].

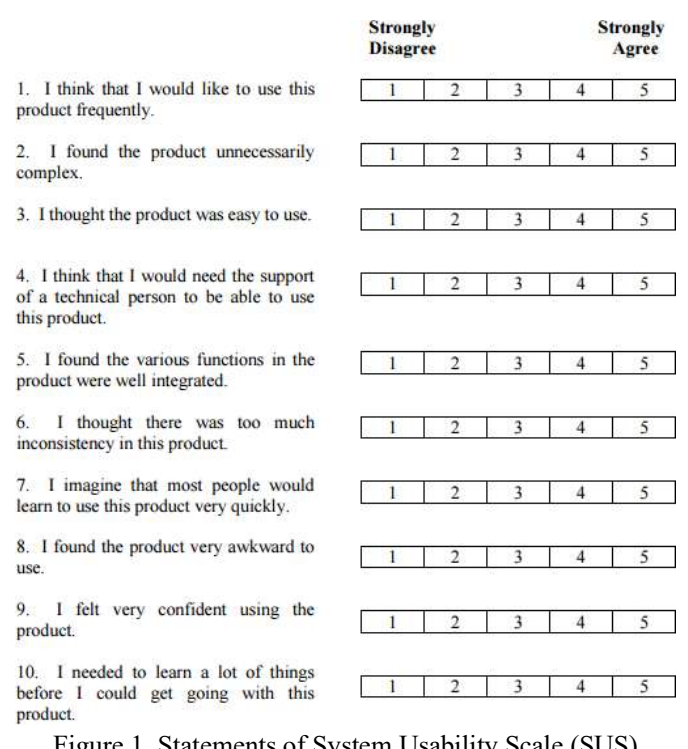

\section{E. Findability}

Findability is a term when there is an easiness to find the information contained on the website, both from the outside the website (using search engines, etc.), or the users can discover it within the relevant website [14]. With findability, it is expected that users can find something easily and quickly on the website [7].

\section{RESEARCH METHOD}

In this research, the research methodology that will be made is shown in Figure 2 below, 


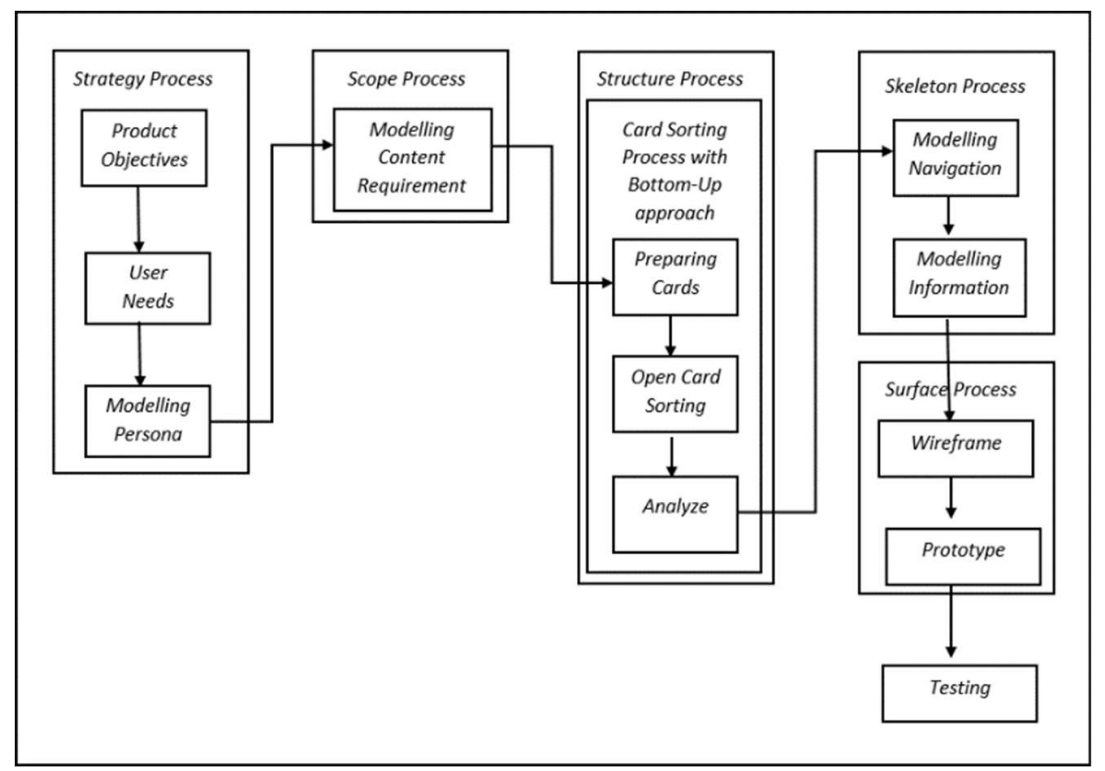

Figure 2. Research Methodology

Five main stages of the user experience elements are used to obtain the information architecture design according to the desires and needs of the users. The stage consists of the following processes:

- The Strategy Process stage is conducted to obtain results from interviews of one of the hospital and the results of questionnaires from users of the hospital website.

- The Scope Process stage is conducted to get any information desired by users of the hospital website.

- The Structure Process stage is conducted by applying a bottom-up approach to the card sorting method to obtain the result of the information architecture design according to the user's desires.

- The Skeleton Process stage is conducted to obtain the results of the navigation model and information model from the information architecture design and then described in the form of a wireframe.

- The Surface Process stage is conducted to change the wireframe into prototype form.

After the five stages are completed, the last process is a test, where there are two tests, namely findability testing, and usability testing.

\section{ANALYSIS AND DiscUSSION}

In this research, the website of Hasan Sadikin Hospital Bandung was used because the website of Hasan Sadikin Hospital Bandung still has some problems related to the availability of information and also with the structure of information, which is still not matched to the users' needs. It was determined from the questionnaire of 30 respondents who have opened the website of Hasan Sadikin Hospital Bandung. They were having difficulties in operating the hospital website, as expressed by some respondents that they are difficult in finding the desired information due to the naming of menus and confusing information grouping. From the difficulties of these respondents, it was also obtained the information from disclosed users with the hope of building the website Hasan Sadikin Hospital Bandung better. Then the information is processed through five stages in 
research methodology undertaken to get the information architecture design in accordance with the desires and needs of users.

\section{A. Strategy Process}

The strategy process is a step that is done to find out the fundamental questions that are needed when building a website. Stage strategy describes Product Objective and User Needs. Product Objective is a factor that comes from the organization concerned, in which Hasan Sakidin Hospital Bandung was interviewed. From the results of the interview obtained that the goal in building the hospital website to increase the access to the hospital website. Hospital website is intended for the public, people that get the benefit of hospital services, other health workers, etc. In the hospital website, users may search for any health information, seek information about health services, information about activities and news about Hasan Sadikin Hospital Bandung Bandung, etc.

User Needs is an external factor that comes from the website users, in which the data collection in the form of questionnaires was conducted to 30 users of Hasan Sakidin Hospital Bandung. The results of the questionnaire obtained that the purpose of the user accessing the hospital website was the same, which is to search for hospital information such as the cost of inpatient rooms, hospital services, doctor schedule, online registration, job vacancy, hospital hours, hospital phone number, hospital address, and other important information. Some users had difficulty in finding the information they need. So, from the 30 respondents, three characteristics of users were formed, it was viewed from the needs of users when accessing the hospital website, the user with the requirements of inpatient, users with outpatient needs and users with other needs.

\section{B. Scope Process}

There are two things done in the scope-process that determine the functional requirements and determine the need for information or content on a website to be built. A functional requirement is a list of functions or features that a website can create, whereas the content requirement is a list of what information will be displayed and in what form [4]. There were 23 pieces of information obtained, namely polyclinics, available services, and unavailable services, doctor's schedules, addresses, telephone numbers, hospital plans, outpatient registration, online registration, specialist doctors, excellent facilities, laboratory services, outpatient costs, hospital profiles, job vacancies, hospital hours, hospital news, national referrals, visiting arrangements, health articles, housekeeping info, inpatient admissions flow, doctor's profile, and insurance.

\section{Structure Process}

This structure stage is the information architecture stage where the content is done to facilitate the understanding of website users [17]. At this stage, the bottom-up approach was used on the method of card sorting. Card sorting method is a method used to assist in building information architecture on a site [18], so the method of card sorting is a method used to improve the findability system [19]. Card sorting methods will also help in understanding user expectations [18]. The bottom-up approach is used because, previously, the data is derived from the user's needs, so in accordance with the bottom-up understanding that departs from the user's needs, then forms a higher structure [17]. In order to manage the content by using card sorting, in accordance with the bottom-up approach, the type of card sorting that is used is open card sorting. The open card sorting method is chosen because this method is used to find out how users group information and label each group of information [18].

Open card sorting was performed by a total of 30 respondents [20]. However, 30 respondents are divided into groups. Thirty respondents were formed into six groups according to the persona. Each group consists of five respondents [21].

In open card sorting, the respondents will be given 23 cards that have been filled with information. So with 23 cards, the respondents were asked to group the cards according to the respondents have the same relationship and category. After the cards are grouped, the respondent is then asked to name each group of cards that have 
been created. Category naming is done freely according to the results of group discussions based on user experience. Open card sorting results are incorporated into a tool called Optimal Workshop [22]. Tools will perform the processing of input from the open card sorting process that has been done before.

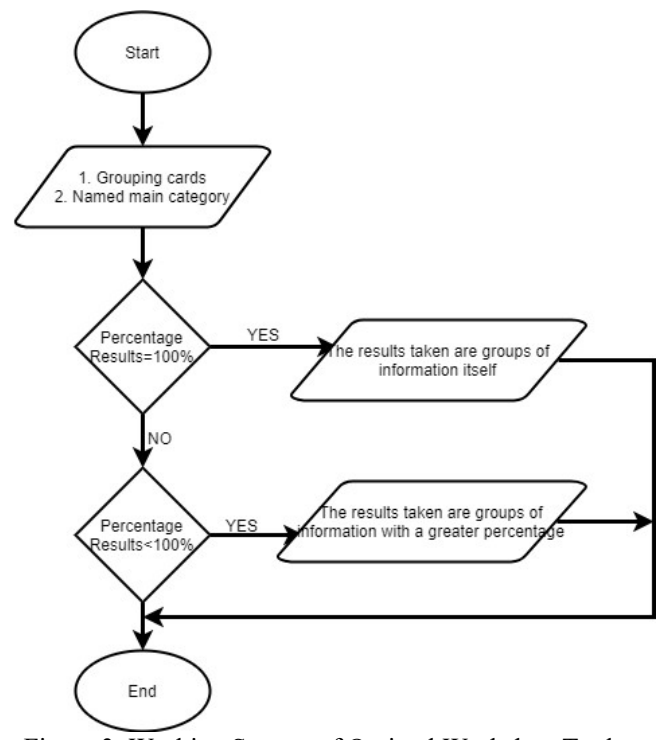

Figure 3. Working System of Optimal Workshop Tools

In Figure 3, the tools receive the respondents' inputs in the form of the grouping of cards and naming the main categories on each group of cards. From the results of input respondents, the next tools do calculations to determine the group of information. The estimate of the percentage of each group of information with the following formula,

$$
\text { Percentage Value }=\frac{\text { respondents who group information in the same category }}{\text { Total of respondents }}
$$

The grouping of information taken is the grouping of information based on percentages. If the information group results show $100 \%$ percentage, then the group of information taken is the information group itself. However, if the information group results show a percentage of less than $100 \%$, then the group of information taken is a group of information that has a greater percentage of other information groups.

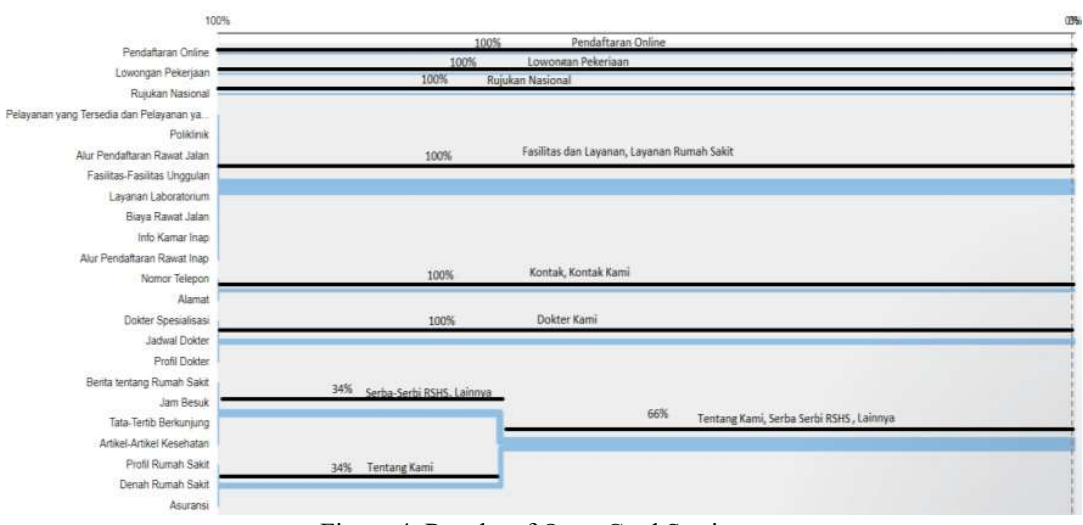

Figure 4. Results of Open Card Sorting 
After the process of open card sorting done and the achieved results, as seen in Figure 4, then the next process is to determine the group of information used in each major category of open card sorting results that can be seen on figure 5 , the architectural information structure design is obtained.

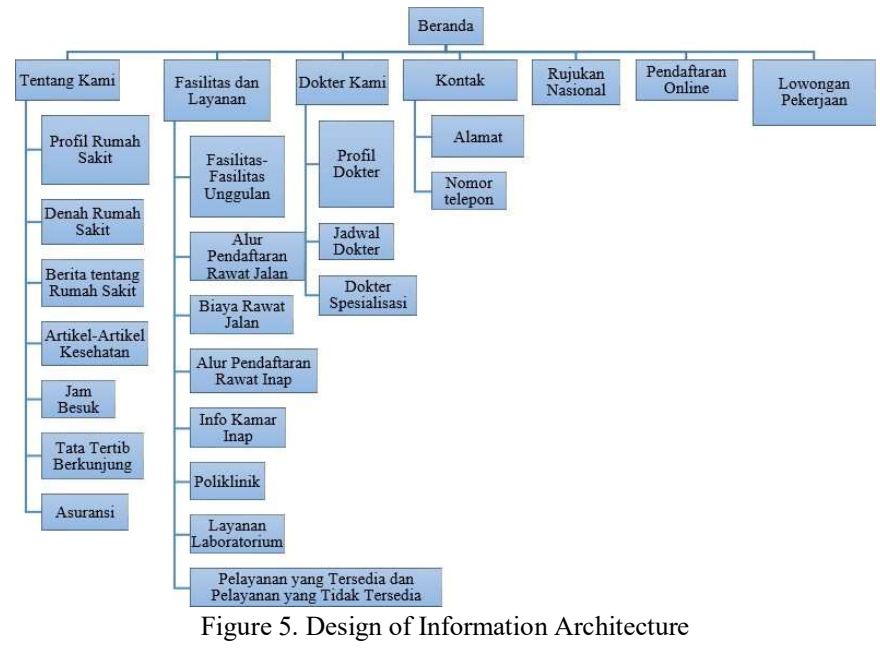

\section{Skeleton Process}

At the skeleton process, this stage discusses the navigation model and information model in information architecture design.

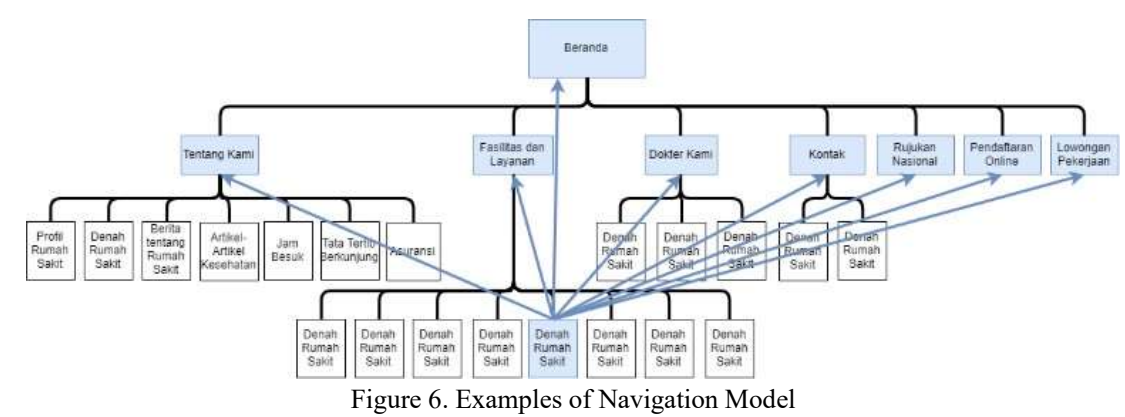

Card sorting can create a navigation model. Navigation is the ability of a website to move from one page to another. As shown in Figure 6, the navigation created is global navigation where users can still open the main page (home page) and other pages on the website directly. For example, when a user is on the Hospital Plan page, the user can also open the information contained on the page of About Us, Facilities and Services, Our Doctor Contact, National Referral, Online Registration, Job Vacancy, and even to the Home page.

In addition, card sorting can also create information models in information architecture design [23]. In the information model, information is made into major categories as seen in the previous information architecture design. After that, the design is applied in wireframe. 


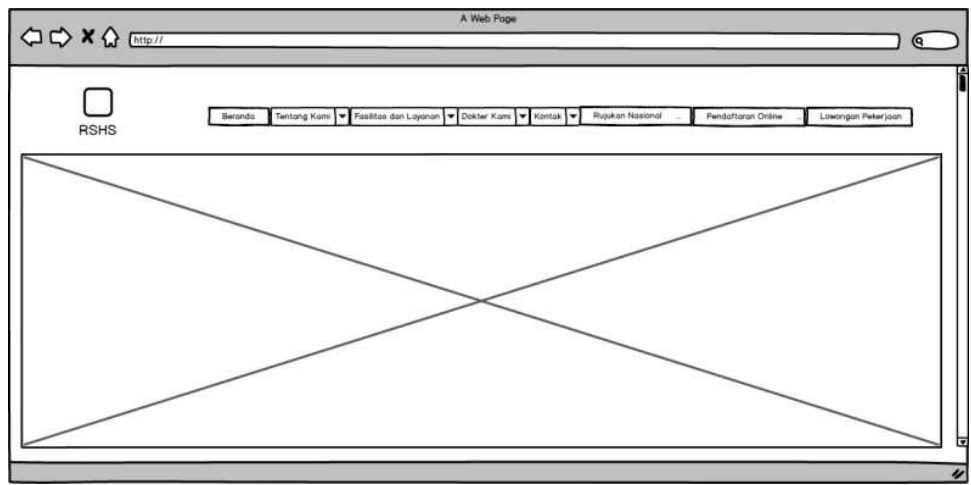

Figure 7. Wireframe of Home Page Website Hasan Sadikin Hospital Bandung

\section{E. Surface Process}

After going through the wireframing process, then the design is implemented into a prototype by following the wireframe design that has been previously created.

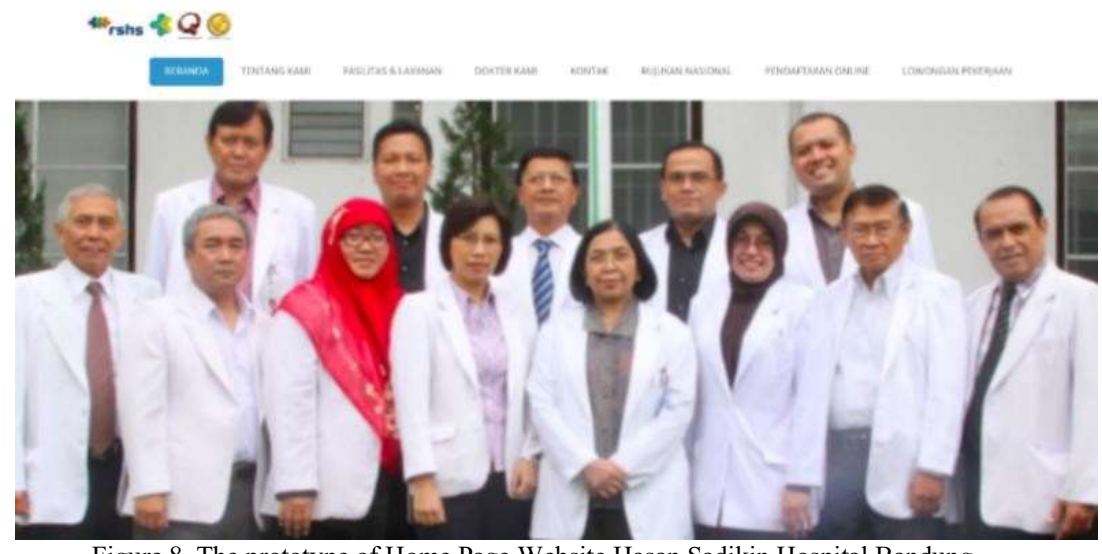

Figure 8. The prototype of Home Page Website Hasan Sadikin Hospital Bandung

\section{RESULTS}

\section{F. Findability Testing}

Findability testing is done to find out the easiness of finding the desired information on the website Hasan Sadikin Hospital Bandung by the users [7]. Findability testing was tested to 30 respondents. In the findability test, the tool used to perform the test is 23 information obtained from the previous stage. The variables involved in the test are the average time required by the respondent in searching for any information. In findability testing, respondents will be given a task to find a piece of information. Each respondent will do 23 tasks that get 23 information obtained from the questionnaire in the previous stage. The task is equally conducted on the website Hasan Sadikin Hospital Bandung, which has no draft information architecture and the website Hasan Sadikin Hospital Bandung that already exists the draft information architecture. After that, the recording time is done when the respondent performs the task given and calculated the average time for each website. Here are the results of findability testing. 


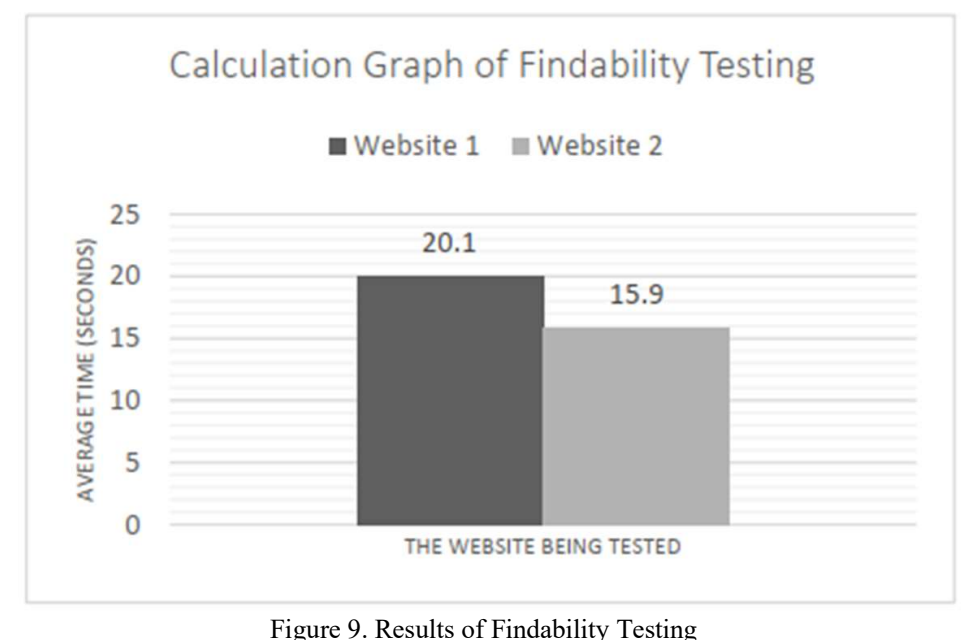

Based on the graph above, the description for website 1 is the website of Hasan Sadikin Hospital Bandung before there is information architecture design. Whereas, website 2 is a website Hasan Sadikin Hospital Bandung after there is information architecture design.

TABLE 1

VARIABLES OF SYSTEM USABILITY SCALE (SUS) STATEMENTS

\begin{tabular}{|c|c|c|}
\hline No. & Statements of SUS & Explanation \\
\hline 1 & $\begin{array}{l}\text { I think that I would like to use this } \\
\text { product frequently }\end{array}$ & $\begin{array}{l}\text { The measured variable is the } \\
\text { respondent's experience in operating the } \\
\text { website }\end{array}$ \\
\hline 2 & $\begin{array}{l}\text { I found the product unnecessarily } \\
\text { complex }\end{array}$ & $\begin{array}{l}\text { The measured variable is the level of } \\
\text { the complexity of the website }\end{array}$ \\
\hline 3 & $\begin{array}{l}\text { I thought the product was easy to } \\
\text { use }\end{array}$ & $\begin{array}{l}\text { The measured variable is the ease of the } \\
\text { website }\end{array}$ \\
\hline 4 & $\begin{array}{l}\text { I think that I would need the } \\
\text { support of a technical person to be } \\
\text { able to use this product }\end{array}$ & $\begin{array}{l}\text { The measured variable is the } \\
\text { involvement of others when the } \\
\text { respondent is accessing the website }\end{array}$ \\
\hline 5 & $\begin{array}{l}\text { I found the various functions in the } \\
\text { product were well-integrated }\end{array}$ & $\begin{array}{l}\text { The measured variable is the } \\
\text { connectedness of one content with other } \\
\text { content in the website }\end{array}$ \\
\hline 6 & $\begin{array}{l}\text { I thought there was too much } \\
\text { inconsistency in this product }\end{array}$ & $\begin{array}{l}\text { The measured variable is inconsistencies } \\
\text { on the website }\end{array}$ \\
\hline 7 & $\begin{array}{l}\text { I imagine that most people would } \\
\text { learn to use this product very } \\
\text { quickly }\end{array}$ & $\begin{array}{l}\text { The measured variable is the ease of the } \\
\text { a user when accessing the website by } \\
\text { stating the speed }\end{array}$ \\
\hline 8 & $\begin{array}{l}\text { I found the product very awkward } \\
\text { to use }\end{array}$ & $\begin{array}{l}\text { The measured variable is the website } \\
\text { difficulties }\end{array}$ \\
\hline 9 & $\begin{array}{l}\text { I felt very confident using the } \\
\text { product }\end{array}$ & $\begin{array}{l}\text { The measured variable is the satisfaction } \\
\text { of the respondent to the website }\end{array}$ \\
\hline 10 & $\begin{array}{l}\text { I needed to learn a lot of things } \\
\text { before I could get going with this } \\
\text { product }\end{array}$ & $\begin{array}{l}\text { The measured variable is the ability of the } \\
\text { respondent when will use the website }\end{array}$ \\
\hline
\end{tabular}


It can be seen that the average time shown on website 1 takes an average time of 20.1 seconds, while on website 2 takes an average time of 15.9 seconds. This time comparison shows that on website 2 requires less time average than website 2 , hence the ability of respondents to find information faster using website 2 compared with using website 1.

\section{G. Usability Testing Using System Usability Scale (SUS)}

Types of usability testing used to test the website of Hasan Sadikin Hospital Bandung existing information architecture design is by using the System Usability Scale (SUS) because it can be used as a parameter in usability measurement. One of them is information architecture [24]. System usability scale testing (SUS) was tested to 30 respondents [25]. The testing tools used are 10 SUS statements that have been translated into Bahasa Indonesia. The variables involved in the test are 10 SUS statements like the following,

In testing using SUS, respondents were asked to rate the hospital website by answering ten SUS statements. Each statement has a scale of 1-5 values. For statements on the odd numbers of 1, 3, 5, 7, and 9 (positive statements, the contribution of values is calculated in a scale position - 1. For statements 2, 4, 6, 8, 10 (negative statements), the values are calculated on a scale of 5 minus the scale position and, further, multiplied by the number of scores with 2.5 to get the overall value of SUS. Here are the results obtained from 30 respondents who conducted testing using SUS.

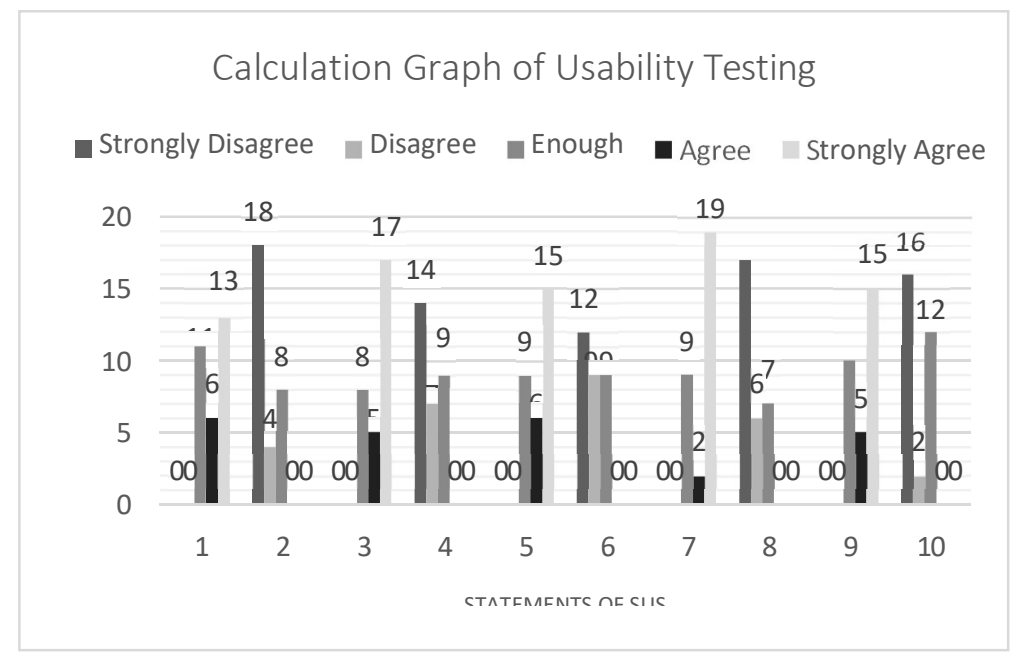

Figure 10. Result of Usability Testing

Based on the graph above, the result of SUS value is 80.33 where the value is above the standard value of either SUS is 68 [26] with the following description,

- $\quad$ Statement number 1 on "I seem to often use this website", in reply to statement number 1, the previous respondent was asked to open repeatedly to better understand the website created, so the respondent at the time of SUS assessment stated strongly agree that the respondent often opens the website.

- Statement number 2 on "I see some parts of this website is quite troublesome," respondents stated strongly disagree if the website is too complex.

- Statement number 3 on "I think this website is easy to use," overall respondents stated strongly agree that the website is easy to use.

- Statement number 4 on "I am likely to require the help of a technician to be able to use this website smoothly", respondents stated disagree if respondents have to use the services of technicians to teach them in operating the website.

- Statement number 5 on "I think the content of this website is well integrated with each other" respondents stated strongly agree that functionality with each other well integrated. 
- Statement number 6 on "I found too many inconsistencies in this website," respondents stated strongly disagree that the website too many inconsistencies.

- Statement number 7 on "I think people will very quickly be able to use this website," respondents who strongly agree that people will very quickly use the website.

- Statement number 8 on "I think this website is very difficult to use," respondents stated strongly disagree if the website is difficult to use.

- In statement number 9 on "I feel satisfied using this website," respondents stated strongly agree that respondents feel comfortable using the website.

- Statement number 10 on "I must learn many things first before starting to use this website," respondents stated strongly disagree if respondents need to learn first before using the website.

\section{CONCLUSION}

Based on testing and analysis conducted on the hospital website, it can be concluded that by using the bottom-up approach in the method of card sorting obtained that the design of information architecture is matched with the desires and needs of users, which can be seen from the evaluation on findability testing, hospital website has been designed with information architecture obtained a fewer time average of 15.9 seconds, compared with Hasan Sadikin Hospital website before there is information architecture design get the average time larger is 20.1 seconds. Thus, the respondents can find information faster in using hospital websites that have been designed with information architecture. Then on the usability testing, the result that obtained is 80.33, where the value has exceeded the standard value of good SUS is 68 , so usability on the hospital website that has been designed with information architecture is good.

\section{REFERENCES}

[1] S. Moustakis, "Website Quality Assesment Criteria," 9th International Conference on Information Quality, 2004.

[2] P. Y. Jiao Guo, "User-Centered Information Architecture of University Library Website," IEEE, 2011.

[3] L. R. Peter Morville, "Defining Information Architecture," in Information Architecture for The World Wide Web, United State of America, O'Reilly Media, Inc, 2006, pp. 3-12.

[4] J. J. Garrett, "The Elements of User Experience," in User Centered Design for The Web and Beyond, Berkeley, CA, Amerika Serikat, Peachpit, 2011, p. 88.

[5] S. M. P. W. Jianming Dong, "A user input and analysis tool for information architecture," CHI '01 Extended Abstracts on Human Factors in Computing Systems, pp. 23-24, 2001.

[6] A. Jain, "Effective Information Architecture for Web Based Systems," International Journal of Advanced Research in Computer Science and Software Engineering, vol. 4, no. 8, pp. 752-757, 2014.

[7] J. Sauro, "How To Measure Findability," MeasuringU, 23 October 2012. [Online]. Available: https://measuringu.com/measure- findability/.

[8] J. H. Heng Belson, "Usability," in Fresh Graduate Guide to Software Development Tools and Technologies, Singapore, 2012.

[9] D. Spencer, "All About Card Sorting," in Card Sorting, Brooklyn, New York, Rosenfeld Media, pp. 4-25.

[10] L. R. Peter Morville, Information Architecture "For The World Wide Web", United State America: O'Reilly, 2006.

[11] D. S. Jakob Nielsen, "Sun Web: user interface design for Sun Microsystem's internal web," Computer Network and ISDN Systems,

vol. 28 , no. 1-2, pp. 179-188, 1995.

[12] J. B. Rashmi Sinha, "Rapid Information Architecture Prototyping," DIS2004, pp. 1-4, 2004.

[13] Aaron Bangor, "Determining What Individual SUS Scores Mean: Adding an Adjective Rating Scale," Journal of Usability Studies, vol. 4, no. 3, pp. 114-123, 2009.

[14] E. K. Jacob, "Information architecture," Annual Review of Information Science and Technology, vol. 43, no. 1, pp. 1-64, 2009.

[15] J. J. Garrett, "The Elements of User Experience," in User Centered Design for The Web and Beyond, Berkeley, CA, Amerika Serikat, Peachpit, 2011, p. 88.

[16] "Card sorting," Usability.gov, [Online]. Available: https://www.usability.gov/how-to-and-tools/methods/card-sorting.html.

[17] D. Spencer, "card sorting: a definitive guide," boxesandarrows, 7 April 2004. [Online]. Available: http://boxesandarrows.com/card- sorting-a-definitive-guide/.

[18] J. Nielsen, "card sorting: how many users to test," Nielsen Norman Group, 19 July 2004. [Online]. Available: 
https://www.nngroup.com/articles/card-sorting-how-many-users-to-test/.

[19] J. Nielsen, "Nielsen Norman Group (Evidence-Based User Experience Research, Training, and Consulting)," 4 June 2012. [Online]. Available: https://www.nngroup.com/articles/how-many-test-users/.

[20] [Online]. Available: https://www.optimalworkshop.com/optimalsort.

[21] J. Robertson, "Information design using card sorting," [Online]. Available: http://www.steptwo.com.au/papers/cardsorting/.

[22] "UX User Experience (User Testing Framework and Questions for Comparative Test)," Stack Exchange, [Online]. Available: https://ux.stackexchange.com/questions/52495/user-testing-framework-and-questions-for-comparative-tests.

[23] B. Rummel, "quick ux assessment? start with the system usability scale," SAP User Experience Community , 6 January 2015. [Online]. Available: https://experience.sap.com/skillup/quick-ux-assessment-start-with-the-system-usability-scale/.

[24] "UJI VALIDITAS DAN RELIABILITAS," Binus University, 1 November 2014. [Online]. Available: http://qmc.binus.ac.id/2014/11/01/u-j-i-v-a-l-i-d-i-t-a-s-d-a-n-u-j-i-r-e-l-i-a-b-i-l-i-t-a-s/.

[25] B. A. P. M, INSTRUMEN PENELITIAN, Bandung: Direktori UPI, 2008.

[26] J. Sauro, "Measuring Usability With The System Usability Scale (SUS)," 2 February 2011. [Online]. Available: https://measuringu.com/sus/. 